\title{
ANALISIS KONTRASTIF PEMBENTUKAN VERBA BAHASA ARAB DAN BAHASA INDONESIA SERTA IMPLIKASINYA DALAM PEMBELAJARAN BAHASA ARAB
}

\author{
Isra Mirdayanti \\ Najmuddin Abd. Safa \\ Kaharuddin \\ Program Studi Linguistik, Fakultas Ilmu Budaya, Universitas Hasanuddin \\ isramirdayanti6@gmail.com \\ najmuddinhas@fs.unhas.ac.id \\ kaharuddintg@yahoo.co.id
}

\begin{abstract}
The construction Arabic dan Indonesian verbs within implication of learning Arabic language. The purpose of this study is to describe the process of formation of verbs Arabic and Indonesian, analyzing the difference between the two processes and outlines the implications of the differences in Arabic and Indonesian verb formation on Arabic learning. This research includes qualitative research. The data in this study are written data, whether published in articles, papers, books, and those contained in other writings related to the formation of verbs Arabic and Indonesian language and learning Arabic. The data collection methods used to refer to the technical note. The data collected in this study were analyzed using contrastive analysis. The results of this study describe the formation of Arabic verbs through internal modification and affixation, while the formation of verbs in the Indonesian language is done through affixation, reduplication and composition. The significant difference between the two is that the formation of verbs in Arabic is always related to time, quantity, and gender so as to reveal time, different numbers or genders are expressed grammatically through verb changes, whereas the formation of verbs in Indonesian is not related to time, and gender so as to reveal semantic concepts of time, quantity, and gender are lexically represented accompanying verbs to form verb phrases without altering their verb forms. The differences between them have implications for the Arabic learning process, namely the emergence of difficulties faced by Arabic learners.
\end{abstract}

Keywords: Morphology, Verb, Learning

\section{A. Latar Belakang}

Bahasa Arab yang kaya akan warisan budayanya tergolong salah satu bahasa yang penting di dunia. Sejak abad pertengahan, bahasa Arab telah diakui sebagai bahasa internasional di samping beberapa bahasa lain seperti, Inggris, Spanyol, Perancis, Rusia, dan Tionghoa. Kedudukann bahasa Arab sebagai bahasa internasional bukan hanya menunjukkan jumlah pemakai bahasa yang banyak, akan tetapi juga karena kedudukannya yang utama dalam sejarah.

Ditinjau dari aspek genealoginya, bahasa Arab termasuk anggota bahasa
Semit kuno sebagaimana halnya bahasa Ibrani, bahasa Yahudi, bahasa Amhar, dan bahasa Aramiy. Meskipun bahasa Arab berasal dari bahasa Semit kuno, bahasa Arab berkembang menjadi bahasa yang sempurna menjelang abad ketiga Masehi sedang pada yang waktu yang sama bahasabahasa yang lain justru mengalami kemunduran. Bahkan beberapa di antaranya ada yang mengalami kepunahan (Nadwi, 2002:11).

Parera (1991: 140) menjelaskan bahwa bahasa di dunia secara morfologis dapat dikelompokkan dalam empat kelompok, yaitu: (1) tipe bahasa isolasi, (2) tipe bahasa 


\section{9 | JURNAL ILMU BUDAYA}

aglutinasi, (3) tipe bahasa fleksi, dan (4) tipe bahasa terpadu. Adapun dari segi strukturnya, bahasa Arab berbeda dengan bahasa Indonesia yang berumpun Austronesia. Perbedaan rumpun bahasa ini berimplikasi pada perbedaan tipologisnya. Rumpun bahasa Semit pada umumnya bertipe fleksi, sedangkan rumpun bahasa Austronesia bertipe aglutinasi.

Bahasa Arab sebagai bahasa fleksi, sistem morfologinya didasarkan pada akar katanya yang trilateral sebagai morfem dasar (Keraf, 1991:67). Verhaar (2001: 101) menjelaskan bahwa morfem akar verba bahasa Arab adalah morfem terbagi, terdiri atas tiga konsonan yang dipisahkan oleh vokal, misalnya morfem akar terbagi \{k-t-b\} mempunyai makna dasar 'tulis'. Morfem ini merupakan dasar bagi pembentukan kata-kata kataba 'dia laki-laki seorang menulis' (lampau), yaktubu 'dia laki-laki seorang menulis' (nonlampau), uktub 'tulislah olehmu seorang laki-laki' (imperatif), maktab 'kantor', k:tib 'penulis', kita:b 'buku', dan lain sebagainya. Contohcontoh ini menunjukkan bahwa pembentukan verba dalam bahasa Arab umumnya melalui modifikasi internal kata tetapi tidak menutup kemungkinan ada juga gejala afiksasi dan pemajemukan. Darwis (2012: 16) menjelaskan bahwa modifikasi internal diartikan sebagai perubahan vokal pada internal sebuah kata.

Lebih lanjut, Haeruddin (2010 : 3) menjelaskan bahwa morfologi bahasa Arab mempunyai sifat inkorporatif, yaitu pemaduan morfem-morfem dasar dengan morfem-morfem lain yang dapat difungsikan dalam sebuah kata tunggal, seperti : katabtuhu 'saya menulisnya'. Bila dianalisis, kata katabtuhu terdiri atas (a) katab- 'menulis' sebagai morfem dasar yang berfungsi sebagai predikat,(b) -tu 'saya' sebagai morfem afiks lekat verba lampau untuk orang pertama tunggal yang berfungsi sebagai penanda subjek, dan (c) hu 'nya 'merupakan morfem afiks lekat nomina untuk orang ketiga tunggal maskulin, yang berfungsi sebagai objek.
Jadi, kata katabtuhu merupakan inkorporasi dari tiga morfem dalam sebuah kata yang berstruktur verba-subjek-objek. Sifat morfologi bahasa Arab yang inkorporasi ini sebenaranya juga dimiliki oleh bahasa Indonesia tetapi jumlahnya sangat kurang, contohnya kumencarinya.

Berbeda dengan bahasa Arab, dalam bahasa Indonesia terdapat tiga proses morfologi, ialah proses pembentukan afiks, proses pengulangan, dan proses pemajemukan. Misalnya, pada kata terjauh, kata jauh terjadi pebubuhan afiks ter- atau disebut afiksasi, pada kata rumah-rumah terjadi proses pengulangan atau reduplikasi, dan pada kata rumah sakit, kata rumah dan kata sakit terjadi proses pemajemukan Selain tiga proses morfologi tersebut, dalam bahasa Indonesia sebenarnya masih ada satu proses lagi yang disebut proses perubahan zero. Proses ini hanya meliputi sejumlah kata tertentu, ialah kata-kata makan, minum, minta, dan mohon, yang semuanya termasuk golongan kata verbal yang transitif. (Ramlan, 1985: 46-47).

Tentu saja sistem pembentukan kata dalam bahasa Arab yang berbeda dengan bahasa Indonesia akan menjadi kendala bagi masyarakat Indonesia dalam mempelajari bahasa Arab. Oleh karena itu, masalah perbedaan sifat morfologi antarkedua bahasa ini memerlukan kajian tersendiri agar dapat memudahkan proses transformasi ilmu bagi para pembelajar bahasa Arab di Indonesia. Berdasarkan hal tersebut, peneliti tertarik melakukan analisis kontrastif pembentukan verba dalam bahasa Arab dan bahasa Indonesia serta implikasinya dalam pembelajaran bahasa Arab.

\section{B. Landasan Teori \\ - Morfologi}

Morfologi merupakan salah satu dari tataran ilmu linguistik yang mempelajari dan menganalisis struktur, bentuk serta klasifikasi kata. Di dalam bahasa Arab 


\section{0 | JURNAL ILMU BUDAYA}

kajian dari morfologi ini disebut dengan تصريف Itaşrî́fl yaitu perubahan satu bentuk kata menjadi bermacam-macam bentukan untuk mendapatkan makna yang berbeda dan tanpa ada perubahan tersebut makna yang berbeda itu tidak akan diperoleh (Alwasilah, 1993: 110).

Sebagai contoh, perubahan bentuk dasar عل l'alimal 'mengetahui' menjadi beberapa bentuk, di antaranya علّم /allama/ 'mengajar', اعلى la'lama/'memberitahukan',

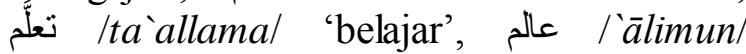
'yang mengetahui' merupakan kajian morfologi. Perubahan bentuk dasar menjadi beberapa bentuk tersebut adalah dengan menambahkan afiks. Penambahan afiks pada contoh di atas ada yang berupa prefiks yaitu pada kata اعلم la lamal dan ada pula yang berupa infiks yaitu pada kata علّم I'allama/ dan عالم /ālimun/ dan ada pula yang berupa gabungan afiks yang ditambahkan pada awal dan di tengah, yaitu pada kata تُعَّم Ita`allamal. Perubahan bentuk

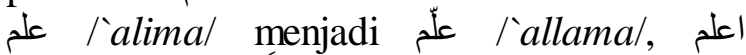
la lamal, dan ita'allamal yang berubah hanya identitas leksikalnya saja sedangkan status kategorialnya tetap, sedangkan

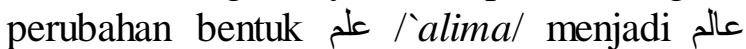
I'àlimun/ yang berubah tidak hanya identitas leksikalnya tetapi juga status kategorialnya. (Khudri, 2004: 6).

Kridalaksana (2008: 142) mengatakan bahwa morfologi adalah bidang linguistik yang mempelajari morfem dan kombinasikombinasinya. Ditambahkannya juga bahwa morfologi merupakan bagian dari struktur bahasa yang mencakup kata dan bagian-bagiannya.

Menurut Nida (1967: 1) morfologi membicarakan seluk-beluk morfem dan susunan morfem dalam pembentukan kata. Lebih lanjut disebutkan juga bahwa di dalam proses pembentukan kata tersebut terdapat pengaruhnya terhadap fungsi dan arti. Sementara itu, Ramlan (1985: 16), mengatakan bahwa morfologi adalah bagian dari ilmu bahasa yang membicarakan seluk-beluk kata serta pengaruh perubahan-perubahan bentuk kata terhadap golongan dan arti kata atau mempelajari seluk-beluk kata serta fungsi perubahan-perubahan bentuk kata itu, fungsi gramatik maupun fungsi semantik.

Verhaar (1997: 52) menyebutkan bahwa morfologi adalah bidang linguistik yang mempelajari susunan bagian-bagian kata secara gramatikal. Dalam bahasa Arab, kata dan seluk-beluknya merupakan kajian ilmu sharf, seperti dikemukakan Dahdah (1992:2) :

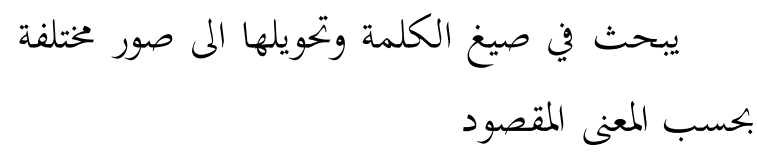

"Pembahasan tentang proses pembentukan kata dan perubahannya ke dalam berbagai bentuk sesuai dengan makna yang dimaksudkan".

Ya`qub (tth: 186), menyebutkan bahwa yang dimaksud dengan morfologi dalam bahasa Arab adalah:

$$
\text { أخذ كلمة من أخرى بتغييرما، مع التناسب في }
$$

/akhżu kalimatin min ukhrā bitagyīri mā, ma`a at-tanāsubi fil mànā/

"Membentuk kata dari kata yang lain dengan berbagai perubahan, namun tetap memiliki hubungan makna".

Sejalan dengan pendapat Ya`qub di atas, Syāhīn (1980: 80) menyebutkan bahwa yang dimaksud dengan morfologi di dalam bahasa Arab adalah:

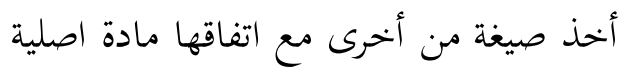

/akhżu ş̣̄gatin ukhrā ma`a infâqihā māddah aşliyyah wa ma`nā/

"Membuat bentuk kata dari kata yang lain dan terjadi perubahan pada bentuk dan makna".

Dari defenisi-defenisi yang telah dikemukakan para linguis tersebut tidak terdapat perbedaan pendapat sehingga dapatlah ditarik sebuah kesimpulan bahwa morfologi adalah bidang linguistik yang mengkaji tentang pembentukan kata dengan cara menggabungkan morfem. 


\section{1 | JURNAL ILMU BUDA YA}

\section{- Verba Bahasa Arab dan Verba Bahasa Indonesia}

Verba merupakan istilah dalam ilmu linguistik yang secara umum berarti kata kerja. Verba dalam bahasa Arab dan bahasa Indonesia tentunya memiliki perbedaan. Berikut ini penjelasan mengenai verba bahasa Arab dan verba bahasa Indonesia.

\section{- Verba Bahasa Arab}

Dalam bahasa Arab, kata kerja disebut dengan $f i$ 'il . Zamakhsyary (2004: 96) mengemukakan definisi $f i$ ' $i l$ sebagai berikut

$$
\text { الفعل مادلّ اقترآن بزمان }
$$

Fi'il adalah (kata) yang menunjukkan suatu peristiwa atau kelakuan yang disertai masa terjadinya.

Ibnu Malik dalam bukunya Matan alAlfiyah menjelaskan batasan dan ciri verba bahasa Arab (fi'il) sebagai berikut :

a. Tidak menerima huruf jar, tanwin, nida', dan alif lam

b. Khusus al-Fi'il al-Madi bisa diakhiri ta' dhamir dan ta' ta'nis sakinah. Contohnya : قمت dan

c. al-Fi'il al-Mudari' dan al-Fi'il al-Amr bisa diakhiri dengan nun at-Taukid dan ya mu'annas mukhatabah, seperti اجتهدى - احفظ

d. al-Fi'il al-Madi dan al-Fi'il al-Mudhari' boleh diikuti kata 'andaian, syarat'

e. Khusus al-Fi'il al-Mudhari' selalu diawali dengan huruf yang tergabung dalam kata انبيت dan boleh diikuti :

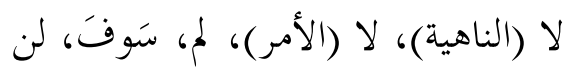

\section{- Verba Bahasa Indonesia}

Kata kerja (verba) adalah kata yang menyatakan tindakan (Ramlan, 1991). Hal yang sama dikemukaan oleh Verhaar (1997: 83), kata kerja (verba) adalah semua kata yang menyatakan perbuatan atau laku, misalnya mengetik, mengutip, meraba, mandi, makan, dan lain-lainnya. Kata kerja atau verba biasanya dibatasi sebagai katakata yang menyatakan perbuatan atau tindakan. Namun, batasan ini masih kabur karena tisak mencakup kata-kata seperti tidur dan meninggal yang dikenal sebagai kata kerja, tetapi tidak menyatakan perbuatan atau tindakan (Keraf, 1991:72). Secara umum, verba dapat dikatakan sebagai kata yang menyatakan perbuatan atau tindakan, proses, dan keadaan yang bukan sifat dan pada umumnya menduduki fungsi predikat dalam kalimat.

Adapun ciri- ciri verba dapat diketahui dengan mengamati :

(1) perilaku semantis,

(2) perilaku sintaksis, dan

(3) bentuk morfologisnya.

\section{PEMBENTUKAN VERBA BAHASA ARAB DAN BAHASA INDONESIA SERTA IMPLIKASINYA DALAM PEMBELAJARAN BAHASA ARAB}

Untuk mengetahui perbedaan (kontrastif) yang terjadi pada pembentukan kata kerja dalam bahasa Arab dan bahasa Indonesia, tentu lebih awal diuraikan bagaimana proses pembentukan verba dalam kedua bahasa ini. Melalui uraian ini dapat dilihat dengan jelas kontrastif yang terjadi dalam proses pembentukan verbanya. Secara gramatikal, deskripsi verbalisasi antara bahasa Arab dan bahasa Indonesia dapat dilihat dalam uraian di bawah ini.

\section{Pembentukan Verba Bahasa Arab}

Pembentukan verba dalam bahasa Arab pada dasarnya dilakukan melalui modifikasi internal, yaitu proses pembentukan kata dengan penambahan unsur-unsur (yang biasanya berupa vokal) ke dalam morfem yang berkerangka tetap (yang biasanya beruba konsonan). Dalam hal ini, bahasa Arab selalu menggunakan modifikasi internal, karena bahasa Arab tidak bisa dibaca tanpa dibantu dengan vokal-vokal (الحركات). Misalnya morfem tetap n-s-r ( ن ر tidak akan bisa dibaca tanpa diberi vokal, misalnya /-a-a-a/ atau /-u-i-a/ sehingga terbentuklah kata: نَصَرَ /nasara/ atau نُصِرَ /nusira/.

Adapun prinsip-prinsip umum pembentukan verba dalam bahasa Arab, yaitu: pertama, pembentukan verba dalam bahasa Arab memiliki prinsip akar dan 


\section{2 | JURNAL ILMU BUDAYA}

Volume 6, Nomor 2, Desember 2018

pola, sehingga verba dalam bahasa Arab selalu berkaitan dengan akar katanya (verba dasar). Kedua, verba dasar dalam bahasa Arab berupa konsonan dan pola tertentu yang terdiri atas vokal dan beberapa konsonan formatif. Selanjutnya vokal-vokal itu difungsikan sebagai infiks, sedangkan konsonan-konsonan formatif tersebut dapat berfungsi sebagai prefiks, sufiks, dan konfiks. Ketiga, pembentukan verba bahasa Arab selalu berdasarkan waktu, jumlah, dan gendernya. Verba berdasarkan waktu terbagi atas lampau (fi'il madhi), sedang dan akan datang (fi'il mudhari'). Adapun jumlahnya terbagi atas satu (mufrad), dua (mutsanna), dan jamak dan gender terbagi atas laki-laki (mudzakkar) dan perempuan (muannats).

\section{a. Prefiks}

Prefiks dalam bahasa arab disebut 'سوابق'. Berikut ini prefiks- prefiks pembentuk verba bahasa arab beserta contoh.

\begin{tabular}{|c|c|c|}
\hline 3 & 2 & 1 \\
\hline $\begin{array}{c}\text { Verba } \\
\text { Bentukan } \\
\end{array}$ & Prefiks & $\begin{array}{l}\text { Verba } \\
\text { Dasar } \\
\end{array}$ \\
\hline ينصر & يَّ & نَصَرَ \\
\hline تنصر & تَ & نصر \\
\hline أنصر & أ & نصر \\
\hline ننصر & نَ & نصر \\
\hline
\end{tabular}

b. Sufiks

Sufiks dalam bahasa arab disebut 'واحق'. Berikut ini Sufiks- Sufiks pembentuk verba bahasa arab beserta contoh dan keterangan waktu, jumlah, dan gendernya.

Sufiks dalam bahasa arab disebut 'لواحق'. Berikut ini Sufiks- Sufiks pembentuk verba bahasa Arab beserta contohnya.

\section{\begin{tabular}{|l|l|l|}
\hline Verba Bentukan & Sufiks & Verba Dasar \\
\hline
\end{tabular}}

\begin{tabular}{|c|c|c|}
\hline نصرا & $L$ & نصر \\
\hline نصروا & lg & نصر \\
\hline نصرتْ & ـــ & نصر \\
\hline نصرتا & تيا & نصر \\
\hline نصرن & ن & نصر \\
\hline نصرت & تـ & نصر \\
\hline نصرتما & تما & نصر \\
\hline نصرتم & تُنْم & نصر \\
\hline نصرتِ & ـتِ & نصر \\
\hline نَصَرَتُنْنَّ & ـانَّ & نصر \\
\hline نصرتُ & تـ & نصر \\
\hline نصرنًا & نَا & نصر \\
\hline
\end{tabular}

c. Konfiks

Konfiks - konfiks pembentuk verba bahasa arab dapat dilihat pada contoh berikut ini.

\begin{tabular}{|c|c|c|}
\hline 3 & 2 & 1 \\
\hline $\begin{array}{c}\text { Verba } \\
\text { Bentukan }\end{array}$ & Konfilks & $\begin{array}{l}\text { Verba } \\
\text { Dasar }\end{array}$ \\
\hline ينصران & يـ / ان & صر \\
\hline ينصرون & يـ /ون & صر \\
\hline تنصران & ت / / ان & صر \\
\hline ينصرن & يـ / ن & صر \\
\hline تنصرون & ت / ون & صر \\
\hline تنصرين & ت / يـن & صر \\
\hline تنصرن & ت الن & صر \\
\hline
\end{tabular}




\section{3 | JURNAL ILMU BUDAYA}

Volume 6, Nomor 2, Desember 2018

\section{Pembentukan Verba dalam Bahasa Indonesia}

Dalam bahasa Indonesia, pembentukan verba dilakukan melalui afiksasi,reduplikasi dan komposisi.

\section{a. Afiksasi}

Pembentukan verba bahasa Indonesia dapat dilakukan melalui prefiksasi, sufiksasi, kombinasi afiks, dan konfiksasi.

\section{Prefiksasi}

Prefiks- prefiks pembentuk verba bahasa Indonesia adalah meng-, ber-, di-, ter-, dan se-.

a. Prefiks meng- dapat membentuk verba transitif maupun verba tak transitif. Berikut ini tiga contoh proses prefiks meng- dalam membentuk verba. Contoh: ejek + prefiks meng- mengejek hindar + prefiks meng- menghind ar siram + prefiks meng- menyiram

b. Prefiks ber- umumnya membentuk verba tak transitif. Berikut ini tiga contoh proses prefiks ber- dalam membentuk verba, yaitu:

$\begin{array}{ll}\text { main + prefiks ber- } & \text { bermain } \\ \text { kerja + prefiks ber- } & \text { bekerja } \\ \text { bagi + prefiks ber- } & \text { berbagi }\end{array}$

c. Prefiks di- umumnya membentuk verba pasif yang merupakan turunan dari verba aktif berprefiks meng-. Berikut ini tiga contoh proses prefiks di- dalam membentuk verba. Contoh:

$\begin{array}{llr}\text { gigit } & \text { menggigit } & \text { digigit } \\ \text { geser } & \text { menggeser } & \text { digeser } \\ \text { angkat } & \text { mengangkat } & \text { diangkat }\end{array}$

d. Prefiks ter- umumnya membentuk verba pasif adversatif. Berikut ini tiga contoh proses prefiks ter- dalam membentuk verba, yaitu:

$$
\begin{array}{ll}
\text { tutup + prefiks ter- } & \text { tertutup } \\
\text { ikat }+ \text { prefiks ter- } & \text { terikat } \\
\text { tahan }+ \text { prefiks ter- } & \text { tertahan }
\end{array}
$$

e. Prefiks per- dapat disebut sebagai afiks deivasional. Afiks ini lebih banyak melekat pada morfem-morfem dasar non verba. Tercatat tiga morfem dasar verba yang dilekatinya. Berikut ini tiga contoh proses prefiks per- dalam membentuk verba dengan melekati verba dasar, yaitu:

buat + prefiks per- $\quad$ perbuat

turut + prefiks per- $\quad$ perturut

sunting + prefiks per- persuntin

f. Prefiks se- sangat kurang penggunaannya dalam lingkungan verba. Contoh:
timpal + prefiks se-
setimpal
ingat + prefiks se-
seingat
tahu + prefiks se-
setahu

\section{Sufiksasi}

Sufiks pembentuk verba bahasa Indonesia hanya ada dua , yaitu -i dan -kan. a. Sufiks -i dapat melekat pada verba dasar. Berikut ini tiga contoh proses sufiks -i dalam membentuk verba dengan melekati morfem dasar verba, yaitu:

$$
\begin{array}{ll}
\text { tanam + sufiksasi }-\mathrm{i} & \text { tanami } \\
\text { siram + sufiksasi }-\mathrm{i} & \text { sirami } \\
\text { kirim + sufiksasi }-\mathrm{i} & \text { kirimi }
\end{array}
$$

b. Sufiks -kan dapat melekat pada verba dasar. Berikut ini tiga contoh proses sufiks -kan dalam membentuk verba dengan melekati morfem dasar verba, yaitu:

$$
\begin{array}{ll}
\text { antar + sufiks -kan } & \text { antarkan } \\
\text { lempar + sufiks -kan } & \text { lemparkan } \\
\text { dengar + sufiks -kan } & \text { dengarkan }
\end{array}
$$

3. Kombinasi Afiks

Afiks kombinasi pembentuk verba

bahasa Indonesia oleh Darwis (2012)

dijabarkan sebagai berikut.

a. Afiks kombinasi meng- /-i

contoh: masuk memasuki

b. Afiks kombinasi meng- /-kan

contoh: ganti menggantikan

c. Afiks kombinasi memper- /-i

contoh: ingat memperingati

d. Afiks kombinasi memper- /-kan

contoh:

tanya mempertanyakan

e. Afiks kombinasi member- /-kan

contoh:

henti berhenti memberhentikan

f. Afiks kombinasi di- /-i

contoh: lalu dilalui

g. Afiks kombinasi di- /-kan 


\section{4 | JURNAL ILMU BUDA Y A}

Volume 6, Nomor 2, Desember 2018 E-ISSN: 2621-5101

contoh:

pulang pulangkan dipulangkan

h. Afiks kombinasi diper- /-i contoh: ingat peringati diperingati

i. Afiks kombinasi diper- /-kan Contoh: main permainkan dipermainkan

j. Afiks kombinasi diber- /-kan

Contoh :

henti berhentikan diberhentikan

\section{Konfiksasi}

Terdapat dua konfiks pembentuk verba dalam bahasa Indonesia, yaitu ber-/ an dan ke-/-an.

a. Konfiks ber-/ -an melekati verba dasar tertentu. Makna gramatikal yang dihasilkannya adalah jamak dan resiprokal. Misalnya: hambur menjadi berhamburan, jatuh menjadi berjatuhan, datang menjadi berdatangan.

b. Konfiks ke-/ -an dapat melekati verba dasar transitif maupun tak transitif. Misalnya: gugur menjadi keguguran, datang menjadi kedatangan, pulang menjadi kepulangan.

\section{b. Reduplikasi}

Merujuk dalam Kridalaksana (1989:

91-93), reduplikasi pembentuk verba terbagi atas 23 bentuk. Secara umum, dari 23 bentuk itu dapat dibagi menjadi tiga bagian, yaitu dwilingga, kombinasi dan konfiks. Berikut ini 3 contoh bentuk reduplikasi pembentuk verba.

a. Reduplikasi Dwilingga

Bentuk reduplikasi dwilingga merupakan pengulangan bentuk dasa kata secara utuh. Tiga contoh pembentukan verba melalui reduplikasi dengan bentuk dwilingga, yaitu:

main main-main,

bongkar bongkar-bongkar, keliling keliling-keliling.

b. Reduplikasi Kombinasi

Bentuk reduplikasi berkombinasi dapat dirumuskan sebagai berikut :

1. meng- $+\mathrm{R}=$ menganglat-angkat, mengada-ada, mengingat- ingat
2. $\mathrm{di}-+\mathrm{R}=$ digigit- gitgit, dicari-cari, ditunggu-tunggu

3. ber- $+R=$ berbisik-bisik, berjalanjalan, bermain-main

4. ter- $+\mathrm{R}=$ terbagi-bagi, terputarputar, tergila-gila

5. meng- $+\mathrm{R}+-$ kan $=$ menghabishabiskan, menggeleng-gelengkan, mengharap-harapkan

6. di- $+\mathrm{R}+-\mathrm{kan}=$ diada-adakan, dibagi-bagikan, dihancurhancurkan.

c. Reduplikasi Konfiks

Bentuk reduplikasi konfiks ini sebenarnya dalam Darwis (2012) digabung menjadi satu bagian dengan bentuk kombinasi yang dinamakan reduplikasi berafiks. Adapun reduplikasi konfiks dalam Kridalaksana (1989) dapat dirumuskan sebagai berikut :

1. $\mathrm{R}+-$ an $=$ cubit-cubitan, tidurtiduran, dua-duan.

2. D+ meng- $\mathrm{R}=$ antar-mengantar, ganti-mengganti, tembak-menembak

3. Ber- $+\mathrm{R}+-$ an $=$ berbalas-balasan, berpeluk-pelukan, berganti-gantian.

\section{c. Komposisi (Pemajemukan)}

Komposisi adalah proses pembentukan verba melalui penggabungan verba dengan verba yang lain atau dengan adjektiva atau dengan nomina yang membentuk sebuah kata dan menghasilkan suatu makna. Adapun Outpout dari proses itu disebut kompositum atau verba majemuk.

Merujuk dalam Darwis (2012), apabila dilihat dari sudut kategori kata yang menjadi atribut atau pendamping letak kanan, verba majemuk bahasa Indonesia dapat dirumuskan sebagai berikut:

a. Verba + Verba $(V+V)$. Contoh: ikut campur, peluk cium, jual beli.

b. Verba + Nomina $(\mathrm{V}+\mathrm{N})$. Contohnya: cuci tangan, mati akal, angkat tangan.

c. Verba + Adjektiva $(\mathrm{V}+\mathrm{A})$. Contohnya: tangkap basah, jual mahal, terus terang. 
d. Adjektiva + Adjektiva (A+ V). Contohnya: berani mati, kurang ajar, luas pandang.

\section{Perbedaan Proses Pembentukan} Verba Antara Bahasa Arab dan Bahasa Indonesia

Perbedaan proses pembentukan verba antara bahasa Arab dan bahasa Indonesia dapat dilihat pada bagan berikut ini:

a. Bahasa arab yang berumpun bahasa semit dan bertipe fleksi, proses pembentukan verbanya dilakukan melalui modifikasi internal dan afiksasi, sedangkan bahasa Indonesia yang berumpun bahasa Austronesia dan bertipe aglutinasi, proses pembentukan verbanya dilakukan melalui afiksasi, reduplikasi, dan pemajemukan.

b. Pembentukan verba dalam bahasa arab selalu berkaitan dengan waktu, jumlah dan gendernya. Sehingga untuk mengungkapkan waktu, jumlah atau gender yang berbeda dinyatakan secara gramatikal melalui perubahan verba, sedangkan Pembentukan verba dalam bahasa Indonesia tidak berkaitan dengan waktu, jumlah dan gendernya. Untuk mengungkapkan konsep- konsep semantis kala, jumlah, dan gender dinyatakan secara leksikal mendampingi verba membentuk frasa verbal, bentuk verbanya tidak berubah.

c. Afiks- afiks pembentuk verba bahasa Arab tidak begitu banyak jumlahnya karena pembentukan verba bahasa Arab berdasarkan pola- pola yang telah ditentukan, sedangkan Afiksafiks pembentuk verba bahasa Indonesia sangat banyak jumlahnya bahkan pada sebuah morfem terdapat berbagai alomorf dan tidak terdapat pola-pola yang telah ditentukan.

4. Implikasi dari analisis kontrastif pembentukan verba bahasa Arab dan bahasa Indonesia terhadap pembelajaran bahasa Arab
Berdasarkan adanya perbedaanperbedaan dalam pembentukan verba dari bahasa Arab dan bahasa Indonesia, tentunya berimplikasi pada pembelajaran bahasa Arab bagi penutur bahasa Indonesia, diantaranya, yaitu para pelajar mengalami kesulitan dalam mempelajari bahasa Arab dan para pengajar diharuskan untuk meningkatkan kompetensi pengajaran.

a. kesulitan- kesulitan yang dihadapi oleh pelajar

Adapun kesulitan- kesulitan yang dihadapi pembelajar bahasa arab diantaranya :

1. Para pelajar mengalami kesulitan dalam pembentukan kata kerja (verba) bentuk lampau (fi'il madhi)

2. Para pelajar mengalami kesulitan dalam pembentukan kata kerja (verba) bentuk sekarang maupun bentuk akan datang ( $f i^{\prime}$ 'l mudhari')

3. Para pelajar menghadapi kesulitan dalam membentuk kata kerja (verba) bentuk lampau (fi'il madhi) dengan jenis subjek yang berbeda

4. Para pelajar menghadapi kesulitan dalam membentuk kata kerja (verba) bentuk sekarang maupun bentuk akan datang (fi'il mudhari') dengan jenis subjek yang berbeda

5. Pembelajar akan kesulitan dalam membentuk kata kerja (verba) bentuk lampau (fi'il madhi) yang dipengaruhi oleh jumlah subjeknya

6. Pembelajar akan kesulitan dalam membentuk kata kerja (verba) bentuk sekarang maupun bentuk akan datang (fi'il mudhari') yang dipengaruhi oleh jumlah subjeknya

Dengan adanya beberapa bentuk kesulitan yang dihadapi oleh para pelajar, tentunya juga berimplikasi pada peningkatan kompetensi guru dalam proses pembelajaran. Secara khusus, kompetensi guru dalam pembelajaran bahasa Arab yang berkaitan dengan pembentukan verba, baik fi'il madhi' maupun fi'il mudhari'. Beberapa kompetensi yang perlu dimiliki 


\section{6 | JURNAL ILMU BUDAYA}

oleh guru dapat dilihat pada uraian berikut ini :

1. Menguasi Karasteristik Pelajar

Langkah awal seorang guru agar dapat melaksanakan fungsi dan tugasnya adalah menguasi karasteristik pelajar. Seorang guru perlu mengenal dan memahami karasteristik pelajarnya agar dapat menyampaikan materinya dengan mudah.

Melalui langkah awal ini, seorang guru bahasa Arab perlu lebih mengenali kemampuan peserta didiknya yang kurang, standar, atau lebih dalam beberapa aspek pembelajaran bahasa Arab, yaitu: mendengarkan dan melafalkan bunyi, membaca dan menulis bahasa Arab, serta menghafal. Dengan memahami kemampuan peserta didiknya, guru akan lebih mudah dalam menentukan strategi, metode maupun media yang akan digunakan.

2. Menguasai kedua bahasa tersebut (bahasa Indonesia dan bahasa Arab).

Setelah menganalisis pembentukan verba dalam bahasa Arab dan bahasa Indonesia yang terlihat jelas kontras di antara keduanya, seorang guru perlu menguasai kedua bahasa tersebut. Hal ini diperlukan agar dapat memberikan penjelasan dengan baik kepada para pelajar.

3. Menguasasi teori belajar dan prinsipprinsip pembelajaran yang mendidik.

Guru harus menguasasi teori belajar dan prinsip-prinsip pembelajaran yang mendidik di antaranya:

a. Guru mampu menggunakan berbagai pendekatan, strategi, metode, dan teknik pembelajaran yang mendidik secara kreatif sesuai dengan standar kompetensi guru. Terkait dengan hal ini, metode klasik yang monoton dalam pembelajaran fi'il madhi dan mudhari' hendaknya dibuat lebih kreatif. Sebagai contoh, guru mengajarkan pola-pola pembentukan verba bahasa Arab dengan gerakan yang unik dan mengandung makna. Hal ini dilakukan agar para pelajar dengan lebih mudah mengingat pelajaran tersebut.

b. Guru mampu menyesuaikan metode pembelajaran yang sesuai dengan karakteristik peserta didik dan memotivasi mereka untuk belajar. Sebagai contoh: apabila guru menemukan pelajar yang pendiam dan pemalu untuk tampil ke depan menghafalkan pola-pola pembentukan verba bahasa Arab, guru hendaknya memotivasi pelajar tersebut. Hal ini disebabkan penggunaaan metode hafalan sangat dianjurkan untuk menghafalkan pola-pola fi'il madhi dan mudhari'.

c. Guru memberi kesempatan kepada peserta didik untuk menguasai materi pembelajaran sesuai usia dan kemampuan belajarnya melalui pengaturan proses pembelajaran dan aktivitas yang bervariasi. Dalam hal ini penyusunan bahan ajar berdasarkan hasil analisis perbedaan antara kedua bahasa tersebut, materi disusun secara terstruktur dari yang lebih mudah hingga yang tersulit.

d. Guru selalu memastikan tingkat pemahaman peserta didik terhadap materi pembelajaran tertentu dan menyesuaikan aktivitas pembelajaran berikutnya berdasarkan tingkat pemahaman tersebut.

e. Guru merencanakan kegiatan pembelajaran yang saling terkait satu sama lain, dengan memperhatikan tujuan pembelajaran maupun proses belajar peserta didik, khususnya pembelajaran pembentukan verba bahasa Arab.

f. Guru memperhatikan respon peserta didik yang belum atau kurang memahami materi pembelajaran yang diajarkan dan menggunakannya untuk memperbaiki rancangan pembelajaran berikutnya. 


\section{7 | JURNAL ILMU BUDAYA}

Volume 6, Nomor 2, Desember 2018

$\begin{array}{llr}\text { Dalam hal ini } & \text { diperlukan } \\ \text { kemampuan } & \text { guru } & \text { dalam } \\ \text { memberikan tips atau cara } & \text { mudah } \\ \text { menghapal pola-pola pembentukan } \\ \text { verba bahasa Arab sangat } \\ \text { dianjurkan. }\end{array}$

4. Penyusunan bahan ajar berdasarkan hasil analisis perbedaan antara kedua bahasa tersebut, materi disusun secara terstruktur dari yang lebih mudah hingga yang tersulit.

5. Penggunaaan metode hafalan sangat dianjurkan untuk menghafalkan tasrif atau pola-pola fi'il madhi dan mudhari'

6. Kemampuan guru dalam memberikan tips atau cara mudah menghapal tasrif sangat dianjurkan.

7. Guru memberikan penjelasan terhadap perbedaan antara verba bahasa Arab dan bahasa Indonesia.

8. Pemberian latihan kepada pembelajar secara intensif tentunya menjadi hal yang utama.

\section{KESIMPULAN}

Terdapat perbedaan pembentukan verba antara bahasa Arab dan bahasa Indonesia, diantaranya : pembentukan verba dalam bahasa arab selalu berkaitan dengan waktu, jumlah dan gendernya sehingga untuk mengungkapkan waktu, jumlah atau gender yang berbeda dinyatakan secara gramatikal melalui perubahan verba. Sedangkan pembentukan verba dalam bahasa Indonesia tidak berkaitan dengan waktu, jumlah dan gendernya. Sehingga untuk mengungkapkan konsep- konsep semantis kala, jumlah, dan gender dinyatakan secara leksikal mendampingi verba membentuk frasa verbal, bentuk verbanya tidak berubah.

Perbedaan pembentukan verba antara kedua bahasa tersebut berimplikasi pada proses pembelajaran kedua bahasa tersebut, terkhusus pada pembelajaran bahasa Arab, yaitu munculnya kesulitan- kesuilitan yang dihadapi oleh pembelajar dan pentingnya peningkatan kemampuan guru dalam mengajarkan bahasa Arab (implikasi pedagogis).

Penelitian tentang analisis kontrastif pembentukan verba dalam bahasa arab dan bahasa Indonesia pada hakikatnya tidak hanya berimplikasi pada pembelajaran bahasa Arab tetapi juga berimplikasi pada pembelajaran bahasa Indonesia, khususnya pembelajaran bahasa Indonesia bagi penutur Asing (Arab). Sementara penelitian ini belum menyentuh ranah tersebut sehingga penulis menyarankan agar dilakukan penelitian lebih lanjut mengenai hal tersebut.

\section{DAFTAR PUSTAKA}

Nadwi, Abu Hasan Ali. 2002. Al-Arab wa al Islam. Damaskus: Al-Maktab Al-Islami.

Parera, Jos Daniel. 1991. Kajian Linguistik Umum Historis Komparatif dan tipologi Struktural. Edisi kedua. Jakarta: Jakarta: PT. Erlangga.

Keraf, Gorys. 1991. Tata Bahasa Rujukan Bahasa Indonesia. Jakarta: PT Grasindo.

Verhaar. 2001. Asas- Asas Linguistik Umum. Cetakan Ketiga. Yogyakarta: Gadjah Mada University Press.

Darwis, Muhammad. 2012. Morfologi Bahasa Indonesia Bidang Verba. Makassar: CV Menara Intan. 